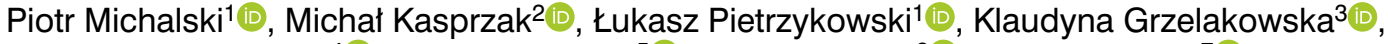

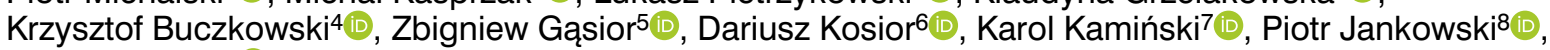
Aldona Kubica ${ }^{1}$

${ }^{1}$ Department of Health Promotion, Collegium Medicum, Nicolaus Copernicus University, Bydgoszcz, Poland

2Department of Cardiology an Internal Medicine, Nicolaus Copernicus University, Collegium Medicum in Bydgoszcz, Poland

${ }^{3}$ Faculty of Medicine, Collegium Medicum in Bydgoszcz, Nicolaus Copernicus University Bydgoszcz, Poland

${ }^{4}$ Department of Family Medicine, Faculty of Medicine, Collegium Medicum, Nicolaus Copernicus University in Bydgoszcz, Poland

${ }^{5}$ Department of Cardiology, Medical University of Silesia, Katowice, Poland

${ }^{6}$ Department of Cardiology and Hypertension with Electrophysiological Lab, Central Research Hospital the Ministry of the Interior and Administration, Warsaw, Poland

${ }^{7}$ Department of Population Medicine and Civilization Diseases Prevention, Medical University of Bialystok, Bialystok, Poland

${ }^{8}$ Department of Epidemiology and Health Promotion, School of Public Health, Centre of Postgraduate Medical Education, Warsaw, Poland

\title{
Ambulatory assessment of medication adherence in high cardiovascular-risk patients. The Polish population of the EUROASPIRE V survey
}

\section{Corresponding author:}

Piotr Michalski, Department of Health Promotion, Collegium Medicum, Nicolaus Copernicus University, Bydgoszcz, Poland

e-mail: michalski.piotr@onet.eu
Medical Research Journal 2021; Volume 6, Number 4, 316-321 10.5603/MRJ.a2021.0053 Copyright (C) 2021 Via Medica ISSN 2451-2591 e-ISSN 2451-4101

\begin{abstract}
Introduction: Patients' non-compliance with therapeutic recommendations is an important factor limiting the effectiveness of the treatment. This study aimed to compare patients' declarations regarding their drug intake (Medication Adherence Questionnaire) with the results of the Adherence in Chronic Disease Scale (ACDS).

Material and methods: The study included 200 patients (66.5\% women) without prior cardiovascular events, diagnosed with hypertension, hypercholesterolemia, or diabetes within 6-24 months before the inclusion. To assess the therapeutic plan implementation the ACDS and the MAQ questionnaires were used.

Results: Based on patients' declarations, a satisfactory level of adherence (MAQ 5 and MAQ 4) was reported for $75.58 \%$ of patients treated for hypertension, $51.62 \%$ for diabetes, and $62.22 \%$ for hypercholesterolemia. A non-adherence risk assessment with the use of the ACDS yielded high results (i.e. low risk of non-adherence) in $38.58 \%$ of hypertension patients, $51.61 \%$ of diabetes patients $41.11 \%$ of hypercholesterolemia patients. Regardless of the disease, the patients indicating full (MAQ 5) or almost full (MAQ 4) therapeutic plan implementation often did not confirm that in similar question 1 of the ACDS.

Conclusions: Patients' self-assessment of the implementation of a therapeutic plan poses a risk of overestimation; particularly when it is based on answering only a single question. Additional application of the ACDS seems to help assess the risk of non-adherence as well as define barriers, beliefs, and behaviors that determine it. This assessment provides the basis to take action to improve the therapeutic plan implementation.

Key words: cardiovascular-risk patients, adherence, self-reported questionnaires
\end{abstract}

Med Res J 2021; 6 (4): 316-321

\section{Introduction}

Patients' non-compliance with therapeutic recommendations is an important factor limiting the effectiveness of the treatment. Only regular drug intake in accordance with given recommendations, i.e. adherence, can result in achieving a set therapeutic goal and protect the patient from negative consequences to their health, social and economic circumstances [1,2].

The simplest and most commonly used method of adherence evaluation is based on patients' declarations about their drug intake. Unfortunately, the information 
Table 1. Characteristics of the study population

\begin{tabular}{llcc}
\hline Parameter & & N & \% \\
\hline Age & $51.49 \pm 13.63$ years & & 66.50 \\
Sex & Woman & 133 & 33.50 \\
& Man & 67 & 15.50 \\
Diabetes & Treated with pharmacotherapy & 31 & 5.00 \\
& Treated with diet and lifestyle changes & 10 & 79.50 \\
Hypertension & No & 159 & 63.50 \\
& Yes & 127 & 36.50 \\
Hypercholesterolemia & No & 73 & 45.00 \\
& Yes & 90 & 110 \\
\hline
\end{tabular}

acquired via this method is characterized by limited credibility. On the other hand, it is a difficult task to make the declarations more objective in ambulatory conditions [3, 4].

The study aimed to compare patients' declarations about their drug intake (Medication Adherence Questionnaire) with the results of the Adherence in Chronic Disease Scale (ACDS).

\section{Material and methods}

In Poland, the EUROASPIRE V study included 200 patients without prior cardiovascular events, diagnosed with hypertension, hypercholesterolemia, or diabetes from 6 to 24 months before the inclusion. The study obtained approval from the Bioethics Committee of the Nicolaus Copernicus University in Torun, Collegium Medicum in Bydgoszcz (approval number KB 587/2017).

The majority of participants were women (66.5\%) and the average age in the analyzed population was $51.49 \pm 13.63$ years. Detailed characteristics of the study group are presented in Table 1.

To assess the therapeutic plan implementation regarding pharmacotherapy a validated ACDS scale and a 6-point questionnaire (MAQ) were used.

The ACDS allows for the assessment of the level of adherence to pharmacotherapy in patients with chronic diseases. It is a validated, free, publicly available tool. The scale consists of 7 questions evaluating compliance with pharmacotherapy. Questions 1-5 pertain to behaviors directly determining adherence while questions 6 and 7 to situations and views influencing it indirectly. The ACDS as well as its interpretation is available on the website: https://www.wnoz.cm.umk.pl/panel/wp-content/uploads/ACDS-English-version.pdf [5].

The MAQ is used for patients' self-assessment of the medication intake. It includes the question How often do you take your medications as prescribed by the doctor? with 6 possible answers: (5) all the time - 100\%; (4) almost all the time - 90\%; (3) most of the time - 75\%; (2) about half of the time; (1) less than half of the time; (0) I do not take the prescribed medications. In the study, the same question was asked separately about the treatment of hypertension, hypercholesterolemia, and diabetes. For the analysis the satisfactory level of therapeutic plan implementation was established as all the time - 100\% (MAQ 5) or almost all the time - 90\% (MAQ 4).

The statistical analysis was carried out using the Statistica 13.0 package (TIBCO Software Inc, California, USA). Continuous variables were presented as means with standard deviations, medians with interquartile range, minimum and maximum value. The Shapiro-Wilk test demonstrated the non-normal distribution of the investigated continuous variables. Therefore, non-parametric tests were used for statistical analysis. For comparisons of the ACDS score between the MAQ levels, the Kruskal-Wallis one-way analysis of variance and multiple comparison tests were used. Results were considered significant at $p<0.05$.

\section{Results}

Patients' subjective assessment of their medication intake under therapeutic recommendations, acquired through the MAQ, is shown in Table 2 for the analyzed diseases.

Based on patients' declarations, a satisfactory level of adherence was reported for $75.58 \%$ of patients treated for hypertension, $51.62 \%$ of patients treated for diabetes, and $62.22 \%$ of patients treated for hypercholesterolemia.

A non-adherence risk assessment with the use of the ACDS yielded high results (i.e. low risk of non-adherence) in $38.58 \%$ of hypertension patients, $51.61 \%$ of diabetes patients, and $41.11 \%$ of hypercholesterolemia patients (Fig. 1). 
Table 2. Patients' declarations of medication intake as per therapeutic recommendations for hypertension, diabetes, and hypercholesterolemia

\begin{tabular}{|c|c|c|c|c|c|c|}
\hline \multirow[t]{2}{*}{ MAQ } & \multicolumn{2}{|c|}{ Hypertension } & \multicolumn{2}{|c|}{ Diabetes } & \multicolumn{2}{|c|}{ Hypercholesterolemia } \\
\hline & $N=127$ & $\%$ & $\mathbf{N}=31$ & $\%$ & $\mathbf{N}=90$ & $\%$ \\
\hline 5 & 69 & 54,33 & 13 & 41.94 & 31 & 34.44 \\
\hline 4 & 27 & 21.25 & 3 & 9.68 & 25 & 27.78 \\
\hline 3 & 5 & 3.95 & 0 & - & 10 & 11.11 \\
\hline 2 & 3 & 2.36 & 0 & - & 6 & 6.67 \\
\hline 1 & 8 & 6.29 & 0 & - & 7 & 7.78 \\
\hline 0 & 15 & 11.82 & 15 & 48.38 & 11 & 12.22 \\
\hline
\end{tabular}

MAQ: How often do you take your medications as prescribed by the doctor?: (5) all the time - 100\%; (4) almost all the time - 90\%; (3) most of the time - 75\%; (2) about half of the time; (1) less than half of the time; (0) I do not take the prescribed. Declarations of taking medication at a level considered satisfactory are marked in gray

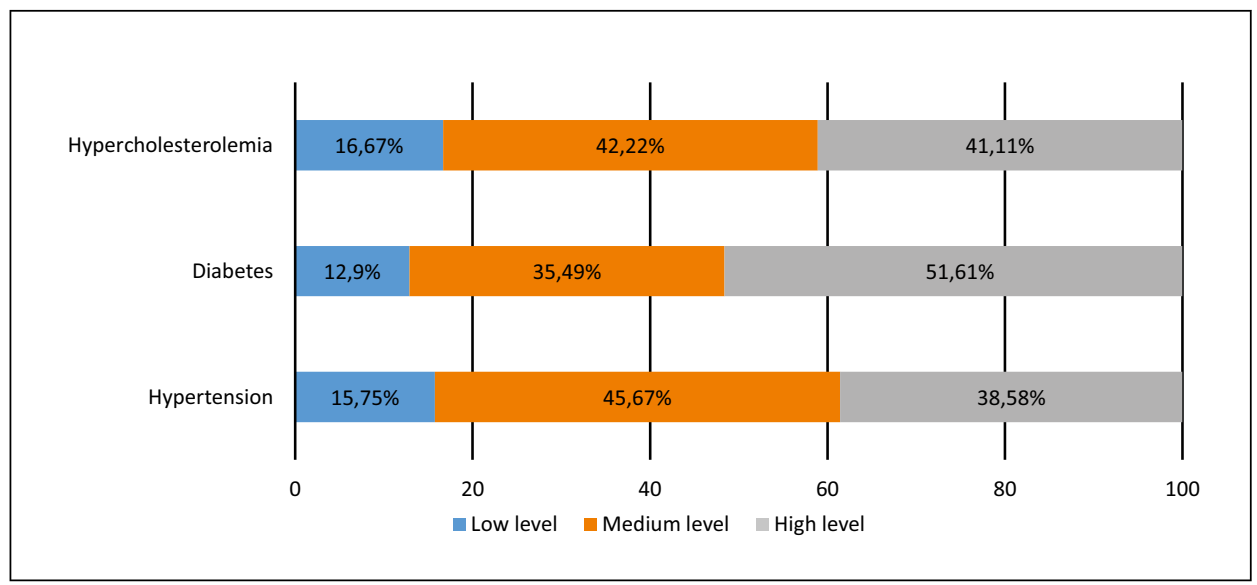

Figure 1. Results of the ACDS for specific diseases

The answers to question 1 of the ACDS (Do you always remember to take all the medications as prescribed by the doctor?) were referred to patients' declarations from the MAQ (How often do you take your medications as prescribed by the doctor?). The mean scores acquired in question 1 of the ACDS in accordance with the $M A Q$ are presented in Table 3 with standard deviations and Min-Max values.

The use of multiple comparison test revealed a significant difference in the ACDS results only in the group of patients with hypertension, between those declaring full therapeutic plan implementation (MAQ 5) and those, who for various reasons, were not taking the prescribed medications (MAQ 0) $(3.81 \pm 0.39$ vs. $3.13 \pm 0.74$; $\mathrm{p}=0.0108)$.

Regardless of the disease, the patients indicating full (MAQ 5), or almost full (MAQ 4), therapeutic plan implementation often did not confirm that in question 1 of the ACDS (Tab. 4).
In subsequent questions 2-5 of the ACDS (assessing direct causes of non-adherence risk during pharmacotherapy) as well as in questions 6 and 7 (assessing indirect causes connected to an improper relationship between the medical personnel and the patient), we did not observe any correlation with the declarations from the MAQ.

\section{Discussion}

Chronic pharmacotherapy is inextricably connected to the issue of patients not following doctors' orders. According to WHO data, this issue applies to approximately half of the patients taking medications [6]. Recognizing the reasons for not starting, stopping, or quitting the therapy seems to be key to improving the results of long-term treatment. Research authors [7-13] point to many risk factors of non-adherence. 


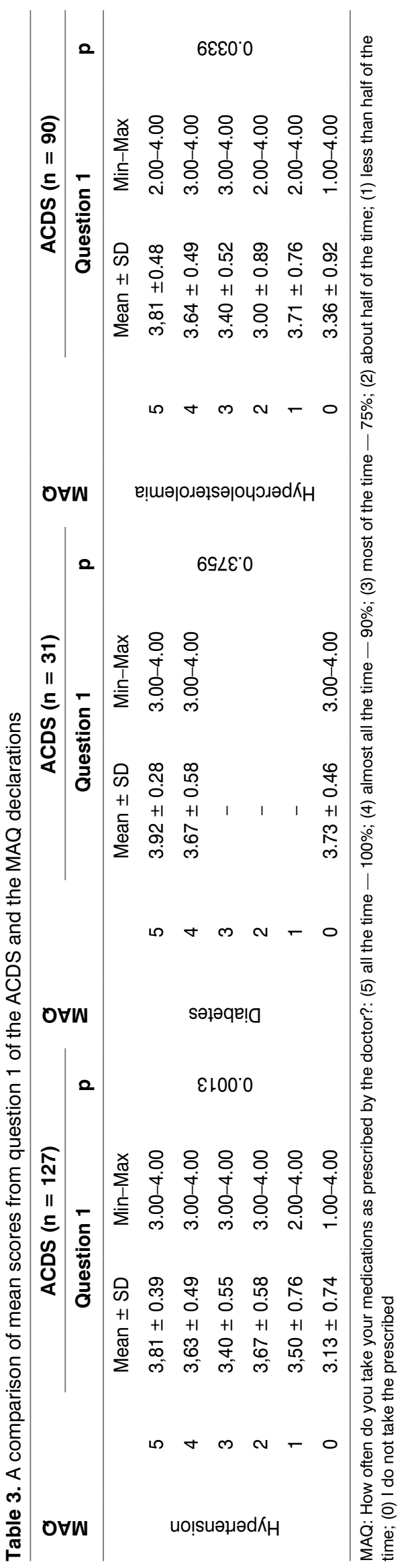

Determinants of adherence include socioeconomic status, the effectiveness of the health care system, patient's health status, as well as type and quantity of medications used $[14,15]$.

Self-assessment performed by patients is an indirect and subjective method of gathering information on the implementation of a therapeutic plan. It is the simplest and the cheapest, and consequently also the most frequently used, method of adherence assessment [16-18].

Based on the MAQ results' analysis, we noted an unexpectedly high percentage of patients declaring adherence in terms of pharmacotherapy on a level of $\geq 90 \%$ in all of the analyzed patient groups. On the other hand, a high score in the ACDS was recorded among a significantly lower percentage $(41.11 \%$ of patients with hypertension, $51.61 \%$ of patients with diabetes, $38.58 \%$ of patients with hypercholesterolemia). To verify such surprising results we compared the MAQ results with a similar question from the ACDS. We discovered that patients declaring full (MAQ 5) or almost full (MAQ 4) implementation of a therapeutic plan often did not confirm this declaration if the question was asked differently (ACDS).

Researchers studying the issue of following therapeutic recommendations draw attention to many factors influencing patients' declarations and behaviors in relation to complying with prescribed pharmacotherapy. Patients often conceal the fact of periodic non-adherence to medication, complete cessation of therapy, or are not fully aware of the mistakes they make $[4,18,19]$.

In our previous evaluation of the adherence to therapeutic recommendations by patients after myocardial infarction based on drug availability, we demonstrated a recommended adherence level (> 80\%) in $44.3 \%$ of patients taking ACEI, $36.1 \%$ of patients taking $\mathrm{P} 2 \mathrm{Y} 12$ receptor inhibitors, and $40.9 \%$ of patients taking statins in a one-year follow-up [20]. In another study, an analysis of 195930 electronic prescriptions indicated that already at the time of initiation of a new treatment, failure to fill prescriptions reaches $28 \%$ [21].

Developing a proper relation with the patient, one based on trust and active listening, as well as the use of questionnaires, can contribute to recognizing barriers involved with failure to follow therapeutic recommendations [22-24], however, the assessment of real adherence requires the use of more precise, objective methods.

\section{Study limitations}

In EUROASPIRE $V$, the adherence level was assessed based on a directly asked question about adherence to recommendations (MAQ). However, in a previous study evaluating the implementation of a therapeutic plan, Kubica et al. [25] point out that patients' answers to a directly asked question about taking prescribed medications do not correlate with the 
Table 4. A comparison of the answers to question 1 of the ACDS and the self-assessment of therapeutic plan implementation (MAQ)

\begin{tabular}{|c|c|c|c|c|c|c|}
\hline \multirow{2}{*}{$\begin{array}{l}\text { MAQ: } \\
\text { How often do you take your } \\
\text { medications as prescribed by the } \\
\text { doctor? }\end{array}$} & \multicolumn{6}{|c|}{$\begin{array}{c}\text { ACDS 1: } \\
\text { Do you always remember to take all the medications as prescribed by } \\
\text { the doctor? }\end{array}$} \\
\hline & Always & $\begin{array}{l}\text { Almost } \\
\text { always }\end{array}$ & Sometimes & $\begin{array}{c}\text { Almost } \\
\text { never }\end{array}$ & Never & Sum \\
\hline \multicolumn{7}{|l|}{ Hypercholesterolemia } \\
\hline MAQ 5 - all the time (100\%) & $26(84.0 \%)$ & $4(13.0 \%)$ & $1(3.0 \%)$ & $0(0.0 \%)$ & $0(0.0 \%)$ & $31(100.0 \%)$ \\
\hline MAQ 4 - almost all the time (90\%) & $16(64.0 \%)$ & $9(36.0 \%)$ & $0(0.0 \%)$ & $0(0.0 \%)$ & $0(0.0 \%)$ & 25 (100.0\%) \\
\hline MAQ 3 - most of the time (75\%) & $4(40.0 \%)$ & $6(60.0 \%)$ & $0(0.0 \%)$ & $0(0.0 \%)$ & $0(0.0 \%)$ & $10(100.0 \%)$ \\
\hline MAQ $2-$ about half of the time & $2(33.3 \%)$ & $2(33.3 \%)$ & $2(33.3 \%)$ & $0(0.0 \%)$ & $0(0.0 \%)$ & $6(100.0 \%)$ \\
\hline MAQ 1 - less than half of the time & $6(86.0 \%)$ & $0(0.0 \%)$ & $1(14.0 \%)$ & $0(0.0 \%)$ & $0(0.0 \%)$ & $7(100.0 \%)$ \\
\hline $\begin{array}{l}\text { MAQ } 0 \text { - I do not take the prescribed } \\
\text { medications }\end{array}$ & $6(55.0 \%)$ & $4(36.0 \%)$ & $0(0.0 \%)$ & $1(9.0 \%)$ & $0(0.0 \%)$ & $11(100.0 \%)$ \\
\hline \multicolumn{7}{|l|}{ Diabetes } \\
\hline MAQ 5 - all the time (100\%) & $12(92.0 \%)$ & $1(8.0 \%)$ & $0(0.0 \%)$ & $0(0.0 \%)$ & $0(0.0 \%)$ & $13(100.0 \%)$ \\
\hline MAQ 4 - almost all the time (90\%) & $2(67.0 \%)$ & $1(33.0 \%)$ & $0(0.0 \%)$ & $0(0.0 \%)$ & $0(0.0 \%)$ & $3(100.0 \%)$ \\
\hline MAQ 3 - most of the time (75\%) & $0(0.0 \%)$ & $0(0.0 \%)$ & $0(0.0 \%)$ & $0(0.0 \%)$ & $0(0.0 \%)$ & $0(0.0 \%)$ \\
\hline MAQ $2-$ about half of the time & $0(0.0 \%)$ & $0(0.0 \%)$ & $0(0.0 \%)$ & $0(0.0 \%)$ & $0(0.0 \%)$ & $0(0.0 \%)$ \\
\hline MAQ $1-$ less than half of the time & $0(0.0 \%)$ & $0(0.0 \%)$ & $0(0.0 \%)$ & $0(0.0 \%)$ & $0(0.0 \%)$ & $0(0.0 \%)$ \\
\hline $\begin{array}{l}\text { MAQ } 0 \text { - I do not take the prescribed } \\
\text { medications }\end{array}$ & $15(100.0 \%)$ & $0(0.0 \%)$ & $0(0.0 \%)$ & $0(0.0 \%)$ & $0(0.0 \%)$ & $15(100.0 \%)$ \\
\hline \multicolumn{7}{|l|}{ Hypertension } \\
\hline MAQ 5 - all the time (100\%) & $56(81.0 \%)$ & $13(19.0 \%)$ & $0(0.0 \%)$ & $0(0.0 \%)$ & $0(0.0 \%)$ & 69 (100\%) \\
\hline MAQ $4-$ almost all the time (90\%) & $17(63.0 \%)$ & $10(37.0 \%)$ & $0(0.0 \%)$ & $0(0.0 \%)$ & $0(0.0 \%)$ & 27 (100.0\%) \\
\hline MAQ 3 - most of the time (75\%) & $2(40.0 \%)$ & $3(60.0 \%)$ & $0(0.0 \%)$ & $0(0.0 \%)$ & $0(0.0 \%)$ & $5(100.0 \%)$ \\
\hline MAQ 2 - about half of the time & $2(67.0 \%)$ & $1(33.0 \%)$ & $0(0.0 \%)$ & $0(0.0 \%)$ & $0(0.0 \%)$ & $3(100.0 \%)$ \\
\hline MAQ $1-$ less than half of the time & $5(63.0 \%)$ & $2(25.0 \%)$ & $1(12 \%)$ & $0(0.0 \%)$ & $0(0.0 \%)$ & $8(100.0 \%)$ \\
\hline $\begin{array}{l}\text { MAQ } 0 \text { - I do not take the prescribed } \\
\text { medications }\end{array}$ & $4(27.0 \%)$ & 10 (67.0\%) & $0(0.0 \%)$ & $0(0.0 \%)$ & 1 (6.0\%) & 15 (100.0\%) \\
\hline
\end{tabular}

real adherence assessed based on drug availability. In that study, $94 \%$ of patients declared following therapeutic recommendations. Yet, the verification based on prescription filling confirmed it only for $54 \%$ of the participants; meaning that $40 \%$ of patients gave an untrue answer to satisfy the doctor [25]. Based on the results of this study, great caution should be exercised when interpreting the MAQ results. The lack of correlation with the ACDS scores seems to confirm those concerns. question. Additional application of the ACDS seems to help assess the risk of non-adherence as well as in defining barriers, beliefs, and behaviors that determine it. This provides the basis to take action to improve the therapeutic plan implementation.

\section{Conflict of interest: None.}

Funding: None:

\section{Conclusions}

Patients' self-assessment of the implementation of a therapeutic plan poses a risk of overestimation; particularly when it is based on answering only a single

\section{References}

1. Kubica A, Grześk G, Sinkiewicz W, et al. Compliance, concordance, adherence w przewlekłej terapii. Folia Cardiol Excerpta. 2010; 5(2): 54-57. 
2. Simpson SH, Eurich DT, Majumdar SR, et al. A meta-analysis of the association between adherence to drug therapy and mortality. BMJ. 2006; 333(7557): 15, doi: 10.1136/bmj.38875.675486.55, indexed in Pubmed: 16790458.

3. Osterberg L, Blaschke T. Adherence to medication. N Engl J Med. 2005; 353: 1972-1974, doi: 10.1056/NEJM200511033531819.

4. Kardas P. Możliwości oceny przestrzegania zaleceń terapeutycznych w praktyce lekarskiej. In: Gaciąg Z, Kardas P. ed. Nieprzestrzeganie zaleceń terapeutycznych. Od przyczyn do praktycznych rozwiązań. Naukowa Fundacja Polfarmy, Warszawa 2015.

5. Buszko K Obońska K, Michalski $P$ et al. The Adherence Scale in Chronic Diseases (ASCD). The power of knowledge: the key to successful patient - health care provider cooperation. Medical Research Journal. 2016; 1(1): 37-42, doi: 10.5603/mri.2016.0006.

6. World Health Organization. Adherence to long-term therapies: evidence for action. http://whqlibdoc.who.int , publications.

7. Kubica A, Kosobucka A, Michalski P, et al. The Adherence in Chronic Diseases Scale - a new tool to monitor implementation of a treatment plan. Folia Cardiol. 2017; 12: 19-26, doi: 10.5603/FC.2016.0000.

8. Kubica A, Kosobucka A, Fabiszak T, et al. Assessment of adherence to medication in patients after myocardial infarction treated with percutaneous coronary intervention. Is there a place for newself-reported questionnaires? Curr Med Res Opin. 2019; 35(2): 341-349, doi: 10.1080/03007995.2018.1510385, indexed in Pubmed: 30091642.

9. Kosobucka A, Michalski P, Pietrzykowski $€$, et al. Adherence to treatment assessed with the Adherence in Chronic Diseases Scale in patients after myocardial infarction. Patient Prefer Adherence. 2018; 12 : 333-340, doi: 10.2147/PPA.S150435, indexed in Pubmed: 29551891.

10. Kubica A, Kasprzak M, Obońska K, et al. Discrepancies in assessment of adherence to antiplatelet treatment after myocardial infarction. Pharmacology. 2015; 95(1-2): 50-58, doi: 10.1159/000371392, indexed in Pubmed: 25592409.

11. Pietrzykowski $Ł$, Kasprzak M, Michalski P, et al. The influence of patient expectations on adherence to treatment regimen after myocardial infarction. Patient Educ Couns. 2021 [Epub ahead of print], doi 10.1016/j.pec.2021.05.030, indexed in Pubmed: 34059362.

12. Pietrzykowski $Ł$, Kasprzak M, Michalski P, et al. Therapy Discontinuation after Myocardial Infarction. J Clin Med. 2020; 9(12), doi 10.3390/jcm9124109, indexed in Pubmed: 33352811

13. Kubica A, Kasprzak M, Siller-Matula J, et al. Time-related changes in determinants of antiplatelet effect of clopidogrel in patients after myocardial infarction. Eur J Pharmacol. 2014; 742: 47-54, doi: 10.1016/j. ejphar.2014.08.009, indexed in Pubmed: 25199965
14. Kardas P, Lewek P, Matyjaszczyk M. Determinants of patient adherence: a review of systematic reviews. Front Pharmacol. 2013; 4: 91, doi: 10.3389/fphar.2013.00091, indexed in Pubmed: 23898295.

15. Sabaté E. (red.): Adherence to long-term therapies: evidence for action. World Health Organization. Geneva 2003.

16. Forbes CA, Deshpande S, Sorio-Vilela F, et al. A systematic literature review comparing methods for the measurement of patient persistence and adherence. Curr Med Res Opin. 2018; 34(9): 1613-1625, doi: 10.1080/03007995.2018.1477747, indexed in Pubmed: 29770718.

17. Anghel LA, Farcas AM, Oprean RN. An overview of the common methods used to measure treatment adherence. Med Pharm Rep. 2019; 92(2): 117-122, doi: 10.15386/mpr-1201, indexed in Pubmed: 31086837

18. Nguyen TM, La Caze A, Cottrell N. What are validated self-report adherence scales really measuring?: a systematic review. Br J Clin Pharmacol. 2014; 77(3): 427-445, doi: 10.1111/bcp.12194, indexed in Pubmed: 23803249.

19. Kubica A, Kosobucka A, Fabiszak T, et al. Assessment of adherence to medication in patients after myocardial infarction treated with percutaneous coronary intervention. Is there a place for newself-reported questionnaires? Curr Med Res Opin 2019; 35(2): 341-349 doi: 10.1080/03007995.2018.1510385, indexed in Pubmed: 30091642

20. Pietrzykowski Ł, Kasprzak M, Michalski P, et al. Medication adherence and its determinants in patients after myocardial infarction. Sci Rep. 2020; 10(1): 12028, doi: 10.1038/s41598-020-68915-1, indexed in Pubmed: 32694522

21. Fischer MA, Stedman MR, Lii J, et al. Primary medication non-adherence: analysis of 195,930 electronic prescriptions. J Gen Intern Med. 2010; 25(4): 284-290, doi: 10.1007/s11606-010-1253-9, indexed in Pubmed: 20131023

22. Kubica A Współpraca z pacjentem - podstawowy warunek skuteczności terapii w chorobie wieńcowej. Choroby Serca i Naczyń. 2009; 6: 131-134.

23. Kubica A, Pietrzykowski t. The therapeutic plan implementation in patients discharged from the hospital after myocardial infarction. Medica Research Journal. 2021; 6(2): 79-82, doi: 10.5603/mrj.a2021.0024.

24. Kubica A, Gruchała M, Jaguszewski M, et al. Adherence to treatment - a pivotal issue in long-term treatment of patients with cardiovascular diseases. An expert standpoint. Medical Research Journal. 2018; 2(4): 123-127, doi: 10.5603/mri.2017.0016.

25. Kubica A. Edukacja zdrowotna na tle wybranych czynników a skuteczność terapii antyagregacyjnej u pacjentów po zawale serca. Wydawnictwo Naukowe Uniwersytetu Mikołaja Kopernika, Toruń 2012 